\title{
The duration of obesity and the risk of type 2 diabetes
}

\author{
Asnawi Abdullah 1,2,*, Johannes Stoelwinder ${ }^{1}$, Susan Shortreed ${ }^{1}$, Rory Wolfe ${ }^{1}$, \\ Christopher Stevenson ${ }^{1}$, Helen Walls ${ }^{1}$, Maximilian de Courten ${ }^{1}$ and Anna Peeters ${ }^{1}$ \\ 'Department of Epidemiology and Preventive Medicine, Alfred Hospital, Monash University, Victoria 3004, \\ Australia: ${ }^{2}$ Department of Biostatistics and Population Health, Faculty of Public Health, University \\ Muhammadiyah Aceh, Indonesia
}

Submitted 4 November 2009: Accepted 13 May 2010: First published online 29 June 2010

\begin{abstract}
Objective: The evidence for the association between obesity and the risk of type 2 diabetes has been derived mainly from the analysis of the degree of obesity. The role of the duration of obesity as an independent risk has not been fully explored. The objective of the present study was to investigate the association between the duration of obesity and the risk of type 2 diabetes.

Design: Prospective cohort study.

Setting: The Framingham Heart Study (FHS), follow-up from 1948 to 1998.

Subjects: A total of 1256 FHS participants who were free from type 2 diabetes at baseline, but were obese on at least two consecutive of the study's twenty-four biennial examinations, were included. Type 2 diabetes status was collected throughout the 48 years of follow-up of the study. The relationship between duration of obesity and type 2 diabetes was analysed using time-dependent Cox models, adjusting for a number of covariates.

Results: The unadjusted hazard ratio (HR) for the risk of type 2 diabetes for men was $1 \cdot 13(95 \%$ CI $1 \cdot 09,1 \cdot 17)$ and for women was $1 \cdot 12(95 \%$ CI $1 \cdot 08,1 \cdot 16)$ per additional 2-year increase in the duration of obesity. Adjustment for sociodemographic variables, family history of diabetes, health behaviour and physical activity made little difference to these HR. For women the evidence of a doseresponse relationship was less clear than for men, particularly for women with an older age at obesity onset.

Conclusions: The duration of obesity is a relevant risk factor for type 2 diabetes, independent of the degree of BMI.
\end{abstract}

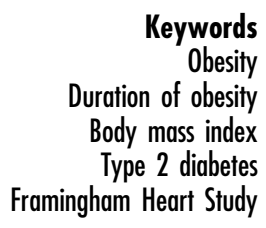

Obesity is clearly associated with type 2 diabetes. Quantification of this association has primarily been accomplished by considering the severity of body weight at one point in time and relating this to the prevalence or incidence of diabetes. The duration of a person's obesity has not been included in risk-prediction equations ${ }^{(1,2)}$ nor has it been taken into account in calculating the population burden of diabetes $^{(1)}$. The potential impact of duration of obesity as an independent risk factor has been neglected. It seems surprising that the risk of diabetes would be identical for people who have been obese for 1 year and who have been obese for 20 years. We hypothesise that such an approach underestimates the association between obesity and risk of type 2 diabetes. With the earlier age of onset, and consequently, duration of obesity in the community increasing, accurate estimates of these relationships are essential for accurate estimation of the future burden of diabetes $^{(2)}$.

The potential importance of the duration of an exposure to disease risk has been acknowledged in many epidemiological studies. For example, in the 1970s several studies showed that the duration of smoking is more important than the intensity of smoking in causing lung cancer $^{(3,4)}$. However, there is a lack of studies examining the association between the duration of obesity and the risk of several chronic diseases. Only six studies have specifically examined the association between the duration of obesity and type 2 diabetes ${ }^{(5-10)}$. Although four of these found a relationship between increased duration of obesity and increased risk of type 2 diabetes, two did not ${ }^{(9,10)}$.

Most of these studies had limitations in the methodology of measuring the duration of obesity. In all but two studies, the measurement of the duration of obesity was retrospective, and relied on the recall of body weight, by asking the history of weight at certain ages ${ }^{(5,7,9,10)}$. It has been pointed out that the recalled body weight approach can induce a significant bias ${ }^{(11,12)}$. Only two studies analysed prospective data from longitudinal cohort studies ${ }^{(5,8)}$. The first of these was conducted in a very specific cultural population setting, the Gila River Indian community of 
Southern Arizona, where the prevalence of obesity and diabetes is relatively high compared with other populations $^{(13)}$. In addition, the results were reported as an incidence of diabetes per person-years of obesity adjusted only for sex, age and current BMI. Other important confounders such as the age of onset of obesity and health behavioursrelated variables were not adjusted for. In the second cohort study $^{(8)}$, the duration of obesity was estimated only from observations at two 5-year intervals. Clearly, a more accurate estimation of the relationship between the duration of obesity and the risk of type 2 diabetes is required.

The aim of the present study was to examine whether the duration of obesity is a risk factor for type 2 diabetes, independent of degree or severity of BMI and other risk factors, using prospectively measured body weight in a long-term cohort study with relatively short intervals between successive examinations.

\section{Research design and methods}

\section{Data source}

We used data from the original cohort study of the Framingham Heart Study (FHS) ${ }^{(14)}$. This cohort study followed up participants (aged 28-62 years at the time of enrolment) for approximately 48 years with examinations at 2-year intervals. Body weight and height were measured every 2 years along with many other potential risk factors of chronic diseases ${ }^{(15)}$. For our analysis, the inclusion criteria were participants having a BMI of $\geq 30.0 \mathrm{~kg} / \mathrm{m}^{2}$ in at least two consecutive examinations during the study, and being free from type 2 diabetes before the onset of obesity ( $n$ 1256).

\section{Duration of obesity}

The beginning of an individual's obesity interval was defined as the first examination of their period of two consecutive occurrences of obesity and the individual was considered to be continuously obese until the first of two consecutive non-obese examinations, death, diagnosis with type 2 diabetes or the end of study for the participants alive until examination 24. Defining the onset of obesity as two consecutive obesity measurements (correlating with approximately 2 years of being continuously obese) accommodated potential misclassification of body weight, particularly between the upper borderline of the 'overweight' BMI category and the lower borderline of the 'obesity' category.

Table 1 presents a hypothetical data set to illustrate our definition of duration of obesity. The obesity interval for participant $\mathrm{C}$ begins at the fourth examination and ends at the fourteenth, their last examination, a total of 20 years. For participant E, the starting point was from examination 12, not from 6 since this participant was not obese in the following examination 7 . In the case of participant $\mathrm{F}$, there were two starting and ending times according to our definition. The first stating point was at examination 4 and the second starting point was at

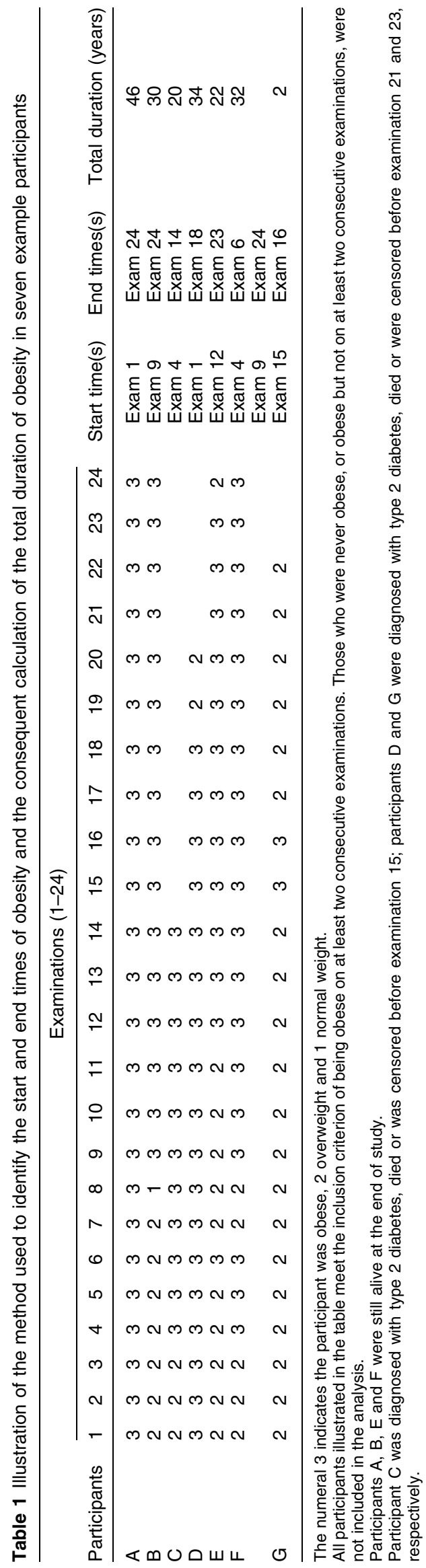


examination 9. The duration of obesity was the sum of these periods of obesity. In the analysis, the duration of obesity was considered to be a time-varying variable with values at a given examination given by the cumulative sum of the duration of obesity to that examination.

\section{Measurement of otber variables}

Baseline measurements were used for variables that did not vary over time and for age. The age of participants was defined as years from date of birth to baseline of study. Education at baseline was grouped into four categories (8th grade or less, high school, college and postgraduate). Ethnicity was categorised as born in the USA or outside the USA. Family history of diabetes was measured at examination 7. Age of onset of obesity was determined as the age when a participant was categorized for the first time as being obese. For participants who were obese at baseline, the age of onset of obesity was their age at the baseline examination. Current marital status, smoking, alcohol consumption and physical activity were included as time-varying variables. Marital status was grouped into three categories (single, married and widowed, divorced or separated). Current smoking status was positive if the participant had smoked regularly in the past year. The average number of cigarettes smoked every day was also included. These variables were measured by intervieweradministered standard questionnaires in all twenty-four examinations. Alcohol consumption was measured in ounces per month, but only in eight examinations (2, 4, 7, 19, 20-23). Physical activity was collected as a continuous score, derived from the number of hours individuals spend daily at different activity levels ${ }^{(16)}$, in four examinations (4, 11, 12, 19).

\section{Measurement of the outcome and time to event}

A person was defined as having type 2 diabetes if the participant had taken insulin and/or an oral hypoglycaemic agent, or if an individual's fasting plasma glucose was $>200 \mathrm{mg} / \mathrm{dl}$ at a given examination. This was the definition that FHS used to categorise participants with diabetes and it is in line with the criteria for type 2 diabetes from the $\mathrm{WHO}^{(17)}$. We defined the date of diabetes incidence as the mid-point between the day of the first examination a participant was recorded as diagnosed with type 2 diabetes and the day of the previous attended examination. Individuals who died or reached the end of the follow-up (examination 24) before developing diabetes were censored at date of death or examination 24 .

\section{Missing values and imputation}

There were missing data in the FHS, as is typical in longitudinal studies. With the exception of BMI, missing values were imputed using the values in the previous examination or the values in the following examination, whichever examination was closer in time. BMI was imputed with a conditional mean estimated by a multiple predictive linear regression model using age at prior examination, sex and several transformations of the previous BMI data (BMI, log BMI, BMI squared and BMI as a categorical variable).

\section{Data analysis}

The relationship between the duration of obesity and incidence of type 2 diabetes was described as a hazard ratio (HR) from a Cox proportional hazards regression using cumulative duration of obesity as a time-dependent covariate $^{(18)}$. The same analysis method was used to subsequently adjust the HR for the time-independent variables of sex, baseline age, age of onset of obesity, education, ethnicity, family history of diabetes and for the time-varying variables of marital status, BMI (per unit BMI), smoking, physical activity and alcohol consumption.

Duration of obesity was included in analyses in one of two exposure model forms; first as a continuous variable assuming a linear dose-response relationship, and second as a four-category variable with categories: $\leq 5,5-14,15-24$, $\geq 25$ years. We performed all analyses separately for men and women, including analyses further stratified by age of onset of obesity. In an analysis of all participants, we included an interaction term between sex and duration of obesity to test whether the relationship between the duration of obesity and incidence of type 2 diabetes was the same for men and women. The analyses were performed using the STATA statistical software package version $10 \cdot 0$ (StataCorp, College Station, TX, USA) ${ }^{(19)}$.

\section{Sensitivity analyses}

A sensitivity analysis was performed to examine whether the association between the duration of obesity and type 2 diabetes incidence might be influenced by the imputation methods of the missing values. To test this assumption, an analysis was performed that included only participants with no missing values of BMI in any examinations. A sensitivity analysis was also performed to test the impact of unknown age of onset of obesity for those obese at baseline by analysing only those without obesity at baseline. The effect of defining duration using two consecutive occurrences of obesity was tested by analysing a simple count of examinations with obesity as a measure of duration. In addition, a sensitivity analysis was also performed comparing the effect of being continuously obese with interrupted periods of obesity.

\section{Results}

The inclusion criteria of no diabetes before onset of obesity and obesity on two consecutive examinations were met by 1256 participants. In all, $47 \%$ of these participants were obese at study baseline and the rest became obese during follow-up; $2 \%$ of the participants were obese continuously from onset of obesity until the 
Table 2 The characteristics of participants who were obese in at least two examinations during study follow-up

\begin{tabular}{|c|c|c|c|c|}
\hline Variables and characteristic & $n$ & $\%$ & Mean & Range \\
\hline Sample & 1256 & & & \\
\hline \multicolumn{5}{|l|}{ Population characteristics } \\
\hline Age at baseline (years) & & & 43 & $28-62$ \\
\hline Age at onset of obesity (years) & & & 52 & $29-88$ \\
\hline \multicolumn{5}{|l|}{ Sex } \\
\hline Men & 494 & 39 & & \\
\hline Women & 762 & 60 & & \\
\hline \multicolumn{5}{|l|}{ Country of birth } \\
\hline Born in USA & 993 & 79 & & \\
\hline Not born in USA & 263 & 21 & & \\
\hline \multicolumn{5}{|l|}{ Marital status at baseline } \\
\hline Single & 99 & 8 & & \\
\hline Married & 1076 & 86 & & \\
\hline Widowed/divorced & 81 & 6 & & \\
\hline \multicolumn{5}{|l|}{ Educational level at baseline } \\
\hline 8th grade or less & 472 & 37 & & \\
\hline High school & 563 & 44 & & \\
\hline College & 121 & 9 & & \\
\hline Postgraduate/school & 131 & 10 & & \\
\hline \multicolumn{5}{|l|}{ Health behaviour } \\
\hline \multicolumn{5}{|l|}{ Smoking status at baseline } \\
\hline Yes & 618 & 49 & & \\
\hline No & 638 & 51 & & \\
\hline Smoking at baseline: number of cigarettes per day & & & $8 \cdot 3$ & $1-60$ \\
\hline Physical activities score at exam 4 & & & 32 & $26-83$ \\
\hline Alcohol drinking at exam 2 (ounces/month) & & & 14 & $0-360$ \\
\hline \multicolumn{5}{|l|}{ Blood pressure } \\
\hline Systolic blood pressure at baseline $(\mathrm{mmHg})$ & & & 142 & $94-300$ \\
\hline Diastolic blood pressure at baseline $(\mathrm{mmHg})$ & & & 89 & $58-155$ \\
\hline \multicolumn{5}{|l|}{ Hypertension at baseline } \\
\hline Yes & 318 & 25 & & \\
\hline No & 938 & 75 & & \\
\hline \multicolumn{5}{|l|}{ Biochemical characteristics } \\
\hline Serum cholesterol at baseline $(\mathrm{mg} / 100 \mathrm{ml})$ & & & 224 & $121-534$ \\
\hline \multicolumn{5}{|l|}{ Body weight characteristics } \\
\hline $\mathrm{BMI}$ at baseline $\left(\mathrm{kg} / \mathrm{m}^{2}\right)$ & & & $29 \cdot 9$ & $18 \cdot 6-46 \cdot 3$ \\
\hline Normal weight $(18 \cdot 5-24 \cdot 9)$ & 142 & 11 & & \\
\hline Overweight $(25 \cdot 0-29 \cdot 9)$ & 583 & 43 & & \\
\hline Obese $(\geq 30 \cdot 0)$ & 586 & 46 & & \\
\hline Obesity duration (years) & & & $15 \cdot 6$ & $2-26$ \\
\hline$\leq 5$ & 264 & 21 & & \\
\hline $5-14$ & 445 & 35 & & \\
\hline $15-24$ & 290 & 23 & & \\
\hline$\geq 25$ & 257 & 21 & & \\
\hline \multicolumn{5}{|l|}{ Diagnosed with type 2 diabetes } \\
\hline Yes & 279 & 22 & & \\
\hline No & 977 & 78 & & \\
\hline
\end{tabular}

end of follow-up. Most people started not obese, then became obese and remained continuously obese till the end of the follow-up. The average duration of followup was 31 years and the mean duration of obesity was 15 years (range from 2 to 46 years). Of the 1256 participants included, 279 (22\%) were diagnosed as having type 2 diabetes during follow-up. The characteristics of these participants are presented in Table 2.

Assuming a linear relationship, the unadjusted HR for the incidence of type 2 diabetes for each additional 2 years of obesity duration was $1 \cdot 13$ (95\% CI $1 \cdot 09,1 \cdot 17)$ for men and $1 \cdot 12(95 \%$ CI $1 \cdot 08,1 \cdot 16)$ for women. Adjustment for the key demographic behavioural variables alone (model A) did not substantially change the HR for either men or women. However, after additional adjustment for time-varying BMI (model B) or adjustment for age of onset of obesity (model $\mathrm{C}$ ), the HR per additional 2 years increase in the duration of obesity was higher in men than in women (Table 3).

In addition to varying according to sex, the effect of additional 2 years' increase in the duration of obesity on type 2 diabetes differed according to the age of onset of obesity categories (Table 4). For men with an age of onset of obesity $<50$ years, the adjusted HR (model A) of type 2 diabetes per additional 2 years' increase in obesity duration was $1 \cdot 11(95 \%$ CI $1 \cdot 04,1 \cdot 17)$ and for those whose age of onset of obesity was $\geq 50$ years, $\mathrm{HR}=1 \cdot 22$ (95\% CI $1 \cdot 10,1 \cdot 34)$. For an age of onset of obesity $<50$ years, women had a similar dose-response relationship to men. 
Table 3 Univariate and multivariate HR of type 2 diabetes risk in two different models of exposure to increasing duration of obesity

\begin{tabular}{|c|c|c|c|c|c|c|c|c|c|}
\hline & \multicolumn{2}{|c|}{$\begin{array}{c}\text { Exposure model 1: HR per additional } \\
2 \text { years duration of obesity }\end{array}$} & \multicolumn{7}{|c|}{$\begin{array}{l}\text { Exposure model 2: HR comparing categories } \\
\text { of duration of obesity to }<5 \text { years }\end{array}$} \\
\hline & \multicolumn{2}{|c|}{$n^{\star}$} & $\leq 5$ years & \multicolumn{2}{|c|}{$5-14$ years } & \multicolumn{2}{|c|}{$15-24$ years } & \multicolumn{2}{|c|}{$\geq 25$ years } \\
\hline Sample & \multicolumn{2}{|c|}{1256} & 245 & \multicolumn{2}{|r|}{446} & \multicolumn{2}{|r|}{306} & \multicolumn{2}{|r|}{259} \\
\hline PYFU & \multicolumn{2}{|c|}{39558} & 20465 & \multicolumn{2}{|c|}{11007} & \multicolumn{2}{|r|}{5221} & \multicolumn{2}{|c|}{2862} \\
\hline Men & \multirow{2}{*}{\multicolumn{2}{|c|}{$\begin{array}{r}494 \\
14841\end{array}$}} & 108 & \multicolumn{2}{|r|}{185} & \multicolumn{2}{|r|}{114} & \multicolumn{2}{|c|}{87} \\
\hline PYFU & & & 8007 & \multirow{2}{*}{\multicolumn{2}{|c|}{$\begin{array}{r}4134 \\
261\end{array}$}} & \multirow{2}{*}{\multicolumn{2}{|c|}{$\begin{array}{r}1845 \\
192\end{array}$}} & \multirow{2}{*}{\multicolumn{2}{|c|}{$\begin{array}{l}853 \\
172\end{array}$}} \\
\hline Women & \multicolumn{2}{|c|}{762} & 137 & & & & & & \\
\hline PYFU & \multicolumn{2}{|c|}{24716} & 12458 & \multicolumn{2}{|r|}{6873} & & 3375 & \multicolumn{2}{|c|}{2009} \\
\hline & $\mathrm{HR}$ & $95 \% \mathrm{Cl}$ & & $\mathrm{HR}$ & $95 \% \mathrm{Cl}$ & $\mathrm{HR}$ & $95 \% \mathrm{Cl}$ & $\mathrm{HR}$ & $95 \% \mathrm{Cl}$ \\
\hline \multicolumn{10}{|l|}{ Univariate } \\
\hline Men & $1 \cdot 13$ & $1 \cdot 09,1 \cdot 17$ & $1 \cdot 00$ & $2 \cdot 6$ & $1 \cdot 5,4 \cdot 4$ & $3 \cdot 4$ & $1 \cdot 9,6 \cdot 1$ & $6 \cdot 9$ & $3 \cdot 7,12 \cdot 9$ \\
\hline Women & $1 \cdot 12$ & $1 \cdot 08,1 \cdot 16$ & $1 \cdot 00$ & $5 \cdot 4$ & $3 \cdot 2,9 \cdot 2$ & $6 \cdot 2$ & $3 \cdot 5,11 \cdot 2$ & $7 \cdot 9$ & $3 \cdot 8,16 \cdot 4$ \\
\hline \multicolumn{10}{|c|}{ Multivariate (model A) } \\
\hline Men & $1 \cdot 13$ & $1 \cdot 09,1 \cdot 17$ & 1.00 & $2 \cdot 5$ & $1 \cdot 5,4 \cdot 4$ & $3 \cdot 3$ & $1 \cdot 8,5 \cdot 9$ & $6 \cdot 4$ & $3 \cdot 4,12 \cdot 1$ \\
\hline Women & $1 \cdot 11$ & $1 \cdot 07,1 \cdot 15$ & $1 \cdot 00$ & $5 \cdot 0$ & $2 \cdot 9,8 \cdot 4$ & $5 \cdot 5$ & $3 \cdot 0,9 \cdot 9$ & $6 \cdot 5$ & $3 \cdot 1,13 \cdot 6$ \\
\hline \multicolumn{10}{|c|}{ Multivariate (model B) } \\
\hline Men & $1 \cdot 11$ & $1 \cdot 07,1 \cdot 16$ & $1 \cdot 00$ & $2 \cdot 3$ & $1 \cdot 4,4 \cdot 0$ & $2 \cdot 8$ & $1 \cdot 5,5 \cdot 3$ & $5 \cdot 1$ & $2 \cdot 5,4 \cdot 0$ \\
\hline Women & $1 \cdot 06$ & $1 \cdot 01,1 \cdot 11$ & $1 \cdot 00$ & $3 \cdot 9$ & $2 \cdot 2,6 \cdot 8$ & $3 \cdot 6$ & $1 \cdot 9,6 \cdot 9$ & $3 \cdot 9$ & $1 \cdot 7,8 \cdot 8$ \\
\hline \multicolumn{10}{|c|}{ Multivariate (model C) } \\
\hline Men & $1 \cdot 11$ & $1 \cdot 05,1 \cdot 16$ & $1 \cdot 00$ & $1 \cdot 8$ & $0 \cdot 9,3 \cdot 6$ & $2 \cdot 3$ & $1 \cdot 1,4 \cdot 8$ & $4 \cdot 3$ & $1 \cdot 8,9 \cdot 9$ \\
\hline Women & $1 \cdot 06$ & $1 \cdot 02,1 \cdot 11$ & $1 \cdot 00$ & $4 \cdot 0$ & $2 \cdot 1,7 \cdot 8$ & $4 \cdot 0$ & $1 \cdot 9,8 \cdot 4$ & $4 \cdot 2$ & $1 \cdot 7,10 \cdot 4$ \\
\hline
\end{tabular}

HR, hazard ratio; PYFU, person-years of follow-up time.

Model A: HR adjusted for sociodemographic variables, i.e. sex, age at baseline, marital status, educational levels, ethnicity (born in the USA or outside the USA), family history of diabetes; and time-varying health behaviour variables, i.e. smoking, alcohol consumption and physical activity.

Model B: HR adjusted for all variables in model A plus time-varying BMI (per unit BMI).

Model C: HR adjusted for all variables in model A plus age of onset of obesity.

${ }^{*} n$ or participants are according to their 'total' duration over period in study.

Table 4 Univariate and multivariate HR of type 2 diabetes per additional 2 years' increase in the duration of obesity and per category of duration of obesity according to the age of onset of obesity

\begin{tabular}{|c|c|c|c|c|c|c|c|c|c|}
\hline \multirow[b]{3}{*}{ Age of onset of obesity } & \multirow{2}{*}{\multicolumn{2}{|c|}{$\begin{array}{l}\text { Increased HR per } \\
\text { additional } 2 \text { years }\end{array}$}} & \multicolumn{7}{|c|}{ HR per categorical duration of obesity } \\
\hline & & & \multirow[b]{2}{*}{$\leq 5$ years } & \multicolumn{2}{|c|}{$5-14$ years } & \multicolumn{2}{|c|}{$15-24$ years } & \multicolumn{2}{|c|}{$\geq 25$ years } \\
\hline & $\mathrm{HR}$ & $95 \% \mathrm{Cl}$ & & $\mathrm{HR}$ & $95 \% \mathrm{Cl}$ & $\mathrm{HR}$ & $95 \% \mathrm{Cl}$ & $\mathrm{HR}$ & $95 \% \mathrm{Cl}$ \\
\hline \multicolumn{10}{|l|}{ Univariate } \\
\hline \multicolumn{10}{|c|}{ Age of onset of obesity ( $<50$ years) } \\
\hline Men & $1 \cdot 12$ & $1 \cdot 05,1 \cdot 19$ & $1 \cdot 00$ & 0.9 & $0 \cdot 4,2 \cdot 4$ & $1 \cdot 6$ & $0 \cdot 7,4 \cdot 2$ & $3 \cdot 4$ & $1 \cdot 3,8 \cdot 7$ \\
\hline Women & $1 \cdot 13$ & $1 \cdot 05,1 \cdot 21$ & $1 \cdot 00$ & $3 \cdot 4$ & $1 \cdot 2,9 \cdot 8$ & $5 \cdot 1$ & $1 \cdot 7,15 \cdot 1$ & $7 \cdot 4$ & $2 \cdot 1,26 \cdot 2$ \\
\hline \multicolumn{10}{|c|}{ Age of onset of obesity ( $\geq 50$ years) } \\
\hline Men & $1 \cdot 23$ & $1 \cdot 14,1 \cdot 32$ & $1 \cdot 00$ & $4 \cdot 2$ & $2 \cdot 1,8 \cdot 5$ & $4 \cdot 1$ & $1 \cdot 6,10 \cdot 9$ & $22 \cdot 1$ & $5 \cdot 4,91 \cdot 0$ \\
\hline Women & $1 \cdot 13$ & $1 \cdot 08,1 \cdot 19$ & $1 \cdot 00$ & $6 \cdot 2$ & $3 \cdot 3,11 \cdot 8$ & $5 \cdot 6$ & $2 \cdot 6,12 \cdot 2$ & $4 \cdot 9$ & $1 \cdot 3,18 \cdot 5$ \\
\hline \multicolumn{10}{|l|}{ Multivariate* $^{*}$} \\
\hline \multicolumn{10}{|c|}{ Age of onset of obesity ( $<50$ years) } \\
\hline Men & $1 \cdot 11$ & $1 \cdot 04,1 \cdot 17$ & $1 \cdot 00$ & $1 \cdot 1$ & $0 \cdot 4,2 \cdot 8$ & $1 \cdot 7$ & $0 \cdot 7,4 \cdot 6$ & $3 \cdot 2$ & $1 \cdot 3,8 \cdot 3$ \\
\hline Women & $1 \cdot 10$ & $1 \cdot 02,1 \cdot 18$ & $1 \cdot 00$ & $2 \cdot 9$ & $1 \cdot 0,8 \cdot 7$ & $3 \cdot 8$ & $1 \cdot 3,11 \cdot 3$ & $5 \cdot 1$ & $1 \cdot 5,17 \cdot 8$ \\
\hline \multicolumn{10}{|c|}{ Age of onset of obesity ( $\geq 50$ years) } \\
\hline Men & $1 \cdot 22$ & $1 \cdot 10,1 \cdot 34$ & $1 \cdot 00$ & $3 \cdot 6$ & $1 \cdot 5,8 \cdot 2$ & $3 \cdot 5$ & $1 \cdot 1,11 \cdot 2$ & $17 \cdot 2$ & $3 \cdot 4,87 \cdot 5$ \\
\hline Women & $1 \cdot 08$ & $1 \cdot 02,1 \cdot 14$ & $1 \cdot 00$ & $4 \cdot 7$ & $2 \cdot 3,9 \cdot 7$ & $4 \cdot 0$ & $1 \cdot 7,9 \cdot 7$ & $2 \cdot 7$ & $0 \cdot 7,10 \cdot 8$ \\
\hline
\end{tabular}

HR, hazard ratio.

*HR adjusted for sociodemographic variables, i.e. sex, age at baseline, marital status, educational levels, ethnicity (born in the USA or outside the USA), family history of diabetes (at examination 7); and time-varying health behaviour variables, i.e. smoking, alcohol consumption and physical activity.

When the duration of obesity was included in the analyses as categories, there was a significant difference in the crude risk of incident type 2 diabetes among the different categories of the duration of obesity. In Table 3, the appropriateness of a dose-response relationship was clear for men. The adjusted HR (model A) in men who were obese for 5-14 years was more than two times higher than in those obese for $\leq 5$ years. For men who were obese for 15-24 years the risk of diabetes was three times higher and approximately six times higher in those obese for $\geq 25$ years compared with men obese for $\leq 5$ years. However, for women, there was no clear dose-response relationship across these categories after full adjustment. When fully adjusted, the risk of type 2 
diabetes in women appeared to increase sharply for durations 5-14 years compared with $\leq 5$ years, but thereafter remained at the same elevated risk (Table 3).

When the analyses were stratified by both age of onset of obesity and sex, the appropriateness of a doseresponse relationship was clear for women with an onset of obesity of $<50$ years of age (Table 4). In women with an age of onset $\geq 50$ years, despite there being evidence of a linear dose-response relationship, the absence of a dose-response relationship across the categories of extended periods of obesity duration suggests that a dose-response relationship is not the most appropriate assumed form for this exposure.

The overall results of analysing the association between the duration of obesity and the risk of type 2 diabetes were not different between a complete case analysis and the analysis using imputed missing values. Nor did the results differ after including/excluding the people who were obese at baseline. The analysis of only those participants who had no missing values of BMI (84.5\% of participants) during follow-up found an adjusted HR (model A) of 1.13 (95\% CI $1 \cdot 04,1 \cdot 23)$ per 2 -year obesity duration, similar to the HR of all included participants, i.e. $1 \cdot 12$ (95\% CI 1·08, 1·15). Exclusion of those participants who were obese at baseline ( $n$ 586, 47\%) was associated with an adjusted HR of $1 \cdot 13$ (95\% CI 1.08, 1.18) per additional 2 years' increase in the duration of obesity. Sensitivity analysis of the effect of the duration of obesity definition also demonstrated a similar finding for duration defined as the total number of examinations with obesity (data not shown).

Sensitivity analysis comparing the effect of being continuously obese for several examinations ( $n$ 1124) compared with interrupted periods of obesity ( $n$ 132) showed a similar adjusted HR (model A) for the group of continuously obese and for the group with interrupted obesity: $\mathrm{HR}=1 \cdot 11$ (95\% CI $1.08,1 \cdot 13)$ and 1.11 (95\% CI 0.99, 1.24) per additional 2 years' obesity duration respectively.

\section{Discussion}

The present study has found that the duration of obesity is significantly associated with an increased risk of developing type 2 diabetes. The association was still significant even after adjusting for current BMI. The exact nature of this exposure-disease relationship differed according to both sex and age of onset of obesity. The effect of additional increases in the duration of obesity appeared to be stronger for men, with each additional 2 years' increase in the duration of obesity associated with an approximately $11 \%$ increased risk of diabetes. A dose-response relationship was clear for men, whereas for women it was apparent in those with an age of onset of obesity of $<50$ years, but less clear for those with older age of onset. Regardless of these differences, in every analysis there was evidence of a longer duration of obesity being associated with increased risk of developing type 2 diabetes.

Nowadays, people are exposed to obesity for longer than in previous decades as a result of the increasing prevalence of obesity at a younger age ${ }^{(2,20)}$. Our results suggest that increasing exposure to obesity might accelerate the incidence of type 2 diabetes in the future. Although the biological mechanism that underlies the association between the duration of obesity and risk of chronic diseases is still unclear, several experimental studies have reported that the duration of obesity might be associated with partial exhaustion of $\beta$ cells ${ }^{(21,22)}$, and the resultant insulinopenia may cause depressed glucose oxidation and impaired glucose tolerance ${ }^{(21)}$. Whether the effect of the duration of obesity is mediated through insulin resistance and/or through the effect on insulin secretion is largely unclarified ${ }^{(23)}$. Resistance to glucose disposal is strongly associated with obesity and results in high fasting and post-load serum insulin concentrations. Prolonged duration of obesity could conceivably worsen this resistance and result in even higher serum insulin concentration. However, a study of residents of the Gila River Indian community of southern Arizona showed a different result ${ }^{(5)}$ and the authors suggested that a long duration of obesity might be associated with a low insulin response rather than with insulin resistance.

Our study was the third study examining the association between the duration of obesity and risk of type 2 diabetes using measured height and weight derived from a prospective cohort study. A key strength of our study was the measurement of weight and height at 2-year intervals for almost 50 years. A further strength of our study was that we were able to adjust for a large number of potential confounding variables including health behaviour-related variables, age of onset of obesity and time-varying BMI.

Our study found a slightly stronger relationship between duration of obesity and risk of diabetes than the two other cohort studies $^{(5,8)}$. In Everhart et al. ${ }^{(5)}$ the participants who were obese for $>10$ years had a risk of diabetes more than double that of those who were obese for $<5$ years. In our study, the risk was almost five times as high (recalculated using similar cut-off points for the duration of obesity to make the results comparable). If our results were compared to Wannamethee and Shaper's ${ }^{(8)}$ study, the risk of diabetes for those who were obese for $>5$ years compared to those who were obese for $<5$ years was three times higher in our study. The differences in our findings are likely to be due to the differences in the study populations and in the analytical methods used.

Variation in the effect of the duration of obesity between men and women was highlighted in our study. In Wannamethee and Shaper's ${ }^{(8)}$ study, the focus was only on men, whereas in the Everhart et al.'s(5) study, although men and women were included in the study, the result was reported for men and women combined. The higher risk of type 2 diabetes per additional 2 years' 
increase in the duration of obesity for men compared with women was particularly strong for women with an older age of obesity onset. The reason for this is as yet unknown and requires further investigation. It is in contrast with the effect of severity of obesity on the risk of diabetes, which is higher for women than men. The gender differences might relate to body composition, insulin resistance, energy balance $^{(24)}$ and fat metabolism ${ }^{(25)}$. In men, greater visceral fat and elevated fat content in the liver are most likely due to the absence of the protective effect of oestrogen found in premenopausal women. This absence leads to increased insulin resistance in individuals with increased visceral adiposity. The exact mechanisms involved have not been identified, but could be related to adipocytokines such as adiponectin, leptin and others.

An important limitation of the present study relates to the sample population. The original Framingham cohort study began in 1948 and the prevalence rates of obesity and type 2 diabetes were relatively low at that time. The prevalence of obesity in the 1950 s was below $10 \%{ }^{(26)}$. It could be argued that the results of the present study might not reflect the current population, in which the prevalence rate of obesity is higher than 50 years ago. In 2008, the prevalence of obesity among adults in the USA had reached approximately $30 \%{ }^{(27)}$. Future research using contemporary, regularly observed body weight from a long-term cohort study is recommended.

The present study analysed the duration of obesity separately from the degree of obesity. Further research analysing the interaction between both degree and duration of overweight and obesity is needed - for example, estimating the risk of type 2 diabetes for every additional excess 'BMI-years' analogous to the 'pack-years' concept used for smoking. It will be important to also determine whether the duration of obesity is an independent predictor of an increased risk of other chronic diseases such as musculoskeletal disease, CVD and cancer. In the future, the duration of obesity needs to be taken into account in calculating the burden of disease and in estimating the future burden of type 2 diabetes.

\section{Conclusion}

The present analysis shows that the duration of obesity is a relevant predictor of the risk of type 2 diabetes, independent of the actual level of BMI. This suggests that in the future we need to take into account the duration of obesity in our obesity prevention strategies to delay the onset of obesity as well as to limit its duration.

\section{Acknowledgements}

The present study received no specific grant from any funding agency in the public, commercial or not-for-profit sectors. A.A. was supported by an AusAID scholarship and
A.P. by a VicHealth Fellowship. The Framingham Heart Study is conducted and supported by the NHLBI in collaboration with study investigators. The manuscript was prepared using a limited access data set obtained from the NHLBI and does not necessarily reflect the opinions or views of the Framingham Heart Study or the NHLBI. The authors have no conflict interest to declare. A.A. designed the study, acquisition of data, review, analysis and interpretation of data, drafting the article and prepared the final version for publication; J.S. designed the study and interpretation of data and reviewing the article and prepared final version for publication; S.S. helped review of data and analysis data, reviewing the article and the result of the manuscript; R.W. helped review of data and analysis data, reviewing the article and the result of the manuscript; C.S. helped review of data and analysis, interpretation of data, reviewing the article and discussion of the manuscript; H.W. helped conduct the literature review, review of data and reviewing the article and the discussion sections of the manuscript; M.C. helped reviewing the article and result and the discussion sections of the manuscript; A.P. helped supervise the implementation of study, designed the study's analytic strategy, reviewing the article and prepared final version for publication. The authors thank the Framingham Heart Study investigators for granting permission to use their data set for the present study.

\section{References}

1. World Health Organization (2008) The Global Burden of Disease: 2004 Update. Switzerland: WHO.

2. Lee JM, Pilli S, Gebremariam A et al. (2010) Getting heavier, younger: trajectories of obesity over the life course. Int J Obes 34, 614-623.

3. Peto R (1986) Influence of dose and duration of smoking on lung cancer rates. IARC Sci Publ 74, 23-33.

4. Doll R \& Peto R (1978) Cigarette smoking and bronchial carcinoma: dose and time relationships among regular smokers and lifelong non-smokers. J Epidemiol Community Health 32, 303-313.

5. Everhart JE, Pettitt DJ, Bennett PH et al. (1992) Duration of obesity increases the incidence of NIDDM. Diabetes $\mathbf{4 1}$, 235-240.

6. Pontiroli AE \& Galli L (1998) Duration of obesity is a risk factor for non-insulin-dependent diabetes mellitus, not for arterial hypertension or for hyperlipidaemia. Acta Diabetologica 35, 130-136.

7. Sakurai Y, Teruya K, Shimada N et al. (1999) Association between duration of obesity and risk of non-insulin-dependent diabetes mellitus. The Sotetsu Study. Am J Epidemiol 149, 256-260.

8. Wannamethee SG \& Shaper AG (1999) Weight change and duration of overweight and obesity in the incidence of type 2 diabetes. Diabetes Care 22, 1266-1272.

9. Hekimsoy Z \& Oktem IK (2003) Duration of obesity is not a risk factor for type 2 diabetes mellitus, arterial hypertension and hyperlipidemia. Diabetes Obes Metab 5, 432-437.

10. Holbrook TL, Barrett-Connor E \& Wingard DL (1989) The association of lifetime weight and weight control patterns with diabetes among men and women in an adult community. Int J Obes 13, 723-729. 
11. Perry GS, Byers TE, Mokdad AH et al. (1995) The validity of self-reports of past body weights by US adults. Epidemiology 6, 61-66.

12. Tamakoshi K, Yatsuya $\mathrm{H}$, Kondo $\mathrm{T}$ et al. (2003) The accuracy of long-term recall of past body weight in Japanese adult men. Int J Obes Relat Metab Disord 27, $247-252$.

13. Leach JD (2008) So Go the Pimas, So Go the Rest of Us. General Interest Article. New Orleans, LA: Paleobiotics Lab; available at http://www.paleobioticslab.com/pima_ diabetes.htm

14. National Heart Institute (1968) The Framingham Study: An Epidemiological Investigation of Cardiovascular Disease. Bethesda, MD: National Institutes of Health.

15. Dawber TR, Meadors GF \& Moore FE Jr (1951) Epidemiological approaches to heart disease: The Framingham Study. Am J Public Health Nations Health 41, 279-286.

16. Kannel WB \& Sorlie P (1979) Some health benefits of physical activity. The Framingham Study. Arch Intern Med 139, 857-861.

17. World Health Organization (2006) Definition and Diagnosis of Diabetes Mellitus and Intermediate Hyperglycemia: Report of a WHO/IDF Consultation. Geneva: WHO.

18. Fisher LD \& Lin DY (1999) Time-dependent covariates in the Cox proportional-hazards regression model. Annu Rev Public Health 20, 145-157.
19. StataCorp LP (2007) Stata Survival Analysis and Epidemiological Tables Reference Manual Release 10. College Station, TX: Stata Corporation.

20. Booth ML, Dobbins T, Okely AD et al. (2007) Trends in the prevalence of overweight and obesity among young Australians, 1985, 1997, and 2004. Obesity (Silver Spring) 15, 1089-1095.

21. Felber JP, Golay A, Jequier E et al. (1988) The metabolic consequences of long-term human obesity. Int J Obes $\mathbf{1 2}$, 377-389.

22. Groop LC \& Eriksson JG (1992) The etiology and pathogenesis of non-insulin-dependent diabetes. Ann Med 24, 483-489.

23. Carlsson S, Persson PG, Alvarsson M et al. (1998) Weight history, glucose intolerance, and insulin levels in middleaged Swedish men. Am J Epidemiol 148, 539-545.

24. Geer EB \& Shen W (2009) Gender differences in insulin resistance, body composition, and energy balance. Gend Med 6, Suppl. 1, 60-75.

25. Blaak E (2001) Gender differences in fat metabolism. Curr Opin Clin Nutr Metab Care 4, 499-502.

26. Centers for Disease Control and Prevention, National Center for Health Statistics (2002) National Health and Nutrition Examination Survey. Atlanta, GA: CDC.

27. Centers for Disease Control and Prevention (2008) Statespecific prevalence of obesity among adults - United States. MMWR 57, 765-768. 